\title{
IMPLEMENTASI WEB CRAWLING UNTUK MENGUMPULKAN INFORMASI WISATA KULINER DI BANDAR LAMPUNG
}

\author{
Raidah Hanifah $^{1}$, Isye Susana Nurhasanah ${ }^{2}$ \\ ${ }^{1}$ Program Studi Teknik Informatika, Institut Teknologi Sumatera \\ ${ }^{2}$ Program Studi Perencanaan Wilayah dan Kota, Institut Teknologi Sumatera \\ Email: ${ }^{1}$ raidah.hanifah@if.itera.ac.id, ${ }^{2}$ isye.susana@pwk.itera.ac.id
}

(Naskah masuk: 6 Juni 2018, diterima untuk diterbitkan: 23 Oktober 2018)

\begin{abstract}
Abstrak
Bandar Lampung merupakan ibu kota Provinsi Lampung yang terletak di ujung pulau Sumatera. Berbeda dengan beberapa Kabupaten di Provinsi Lampung yang memiliki banyak potensi wisata alam, Bandar Lampung sebagai pusat kota tidak banyak memiliki potensi wisata alam. Namun, kota Bandar Lampung masih memiliki potensi untuk mengembangkan wisata kulinernya. Untuk menangkap peluang ekonomi dari wisata kuliner, salah satu caranya adalah dengan membuat pemetaan lokasi-lokasi wisata kuliner strategis yang telah dan berpotensi untuk berkembang, serta membuat perencanaan dan program pengembangan wisata kuliner beserta dengan promosinya yang efektif dan optimal. Sebelum hal tersebut dilakukan, tentunya dibutuhkan informasi terkait kondisi wisata kuliner yang ada saat ini, seperti berapa jumlah wisata kuliner dan letak persebaran lokasinya. Sayangnya, informasi tersebut belum diakomodasi oleh pemerintah kota Bandar Lampung. Informasi terkait kuliner di Bandar Lampung justru tersedia di berbagai website dan media sosial lainnya, mengingat saat ini orang senang berbagi informasi melalui internet. Oleh karena itu, penelitian ini bertujuan untuk mengumpulkan informasi kuliner di Bandar Lampung yang tersebar di web. Untuk mencapai tujuan tersebut, dilakukan penggalian web (web mining) untuk mendapatkan informasi terkait wisata kuliner di Bandar Lampung dengan metode web crawling. Hasil web crawling dari website TripAdvisor, didapatkan berbagai macam informasi seperti nama restoran, alamat, nomor telepon, rating serta jumlah orang yang me-review kuliner tersebut. Informasi yang telah dikumpulkan tersebut dapat dianalisis lebih lanjut untuk berbagai kebutuhan, seperti analisis spasial persebaran objek wisata kuliner, analisis rasio perkembangan jumlah wisata kuliner terhadap jumlah wisatawan yang datang, perencanaan pengembangan wisata kuliner di suatu wilayah secara spesifik maupun komprehensif, serta lokasi dan jenis kuliner yang paling diminati.
\end{abstract}

Kata kunci: web mining, web crawling, wisata kuliner, bandar lampung, tripadvisor.

\section{WEB CRAWLING IMPLEMENTATION FOR COLLECTING CULINARY TOURISM INFORMATION IN BANDAR LAMPUNG}

\begin{abstract}
Bandar Lampung is the capital city of Lampung Province which is located on the edge of the Sumatera island. Unlike some regencies in Lampung Province which have a lot of potential natural tourism, Bandar Lampung as a capital city does not have much. However, Bandar Lampung city still has the potential to develop its culinary tourism. To capture the economic opportunities of culinary tourism, one of the way is to map strategic culinary tourism locations that have developed and potentially develop, and create a comprehensive planning and programs for culinary tourism development along with effective and optimal promotion. But before that, information regarding the current conditions of culinary tourism is needed; for instance, how many and where the location of the culinary tourism are in Bandar Lampung area. Unfortunately, this information has not accomodate yet by the municipility government. Culinary information in Bandar Lampung is actually available on various websites and other social media, considering that currently people like to share information via the internet. So, this study aim is to collect culinary tourism information in Bandar Lampung that sprawl in web. In accomplishing the goal, this research conducts web mining to get information related to culinary tourism in Bandar Lampung by web crawling method. The results of web crawling from the TripAdvisor website such as restaurant name, address, telephone number, rating and the number of people who reviewed the culinary. The result of this research can be use for further analysis with difference approach and goals, such as spatial analysis of culinary tourism sprawl, analysis the impact of culinary tourism development to the number of tourists coming, culinary tourism development and planning in certain region, as well as the type and location of favorable culinary in Bandar Lampung.
\end{abstract}

Keywords: web mining, web crawling,culinary tourism, bandar lampung, tripadvisor. 


\section{PENDAHULUAN}

Provinsi Lampung dapat dikatakan sebagai gerbang Pulau Sumatera. Secara geografis provinsi Lampung terletak di paling selatan pulau Sumatera, sehingga tidak mengherankan jika provinsi Lampung menjadi penghubung sekaligus pintu masuk ke pulau Sumatera dari pulau Jawa. Saat ini Provinsi Lampung sudah dikenal sebagai alternatif tempat untuk berwisata. Beberapa tempat wisata terkenal di Provinsi Lampung, yaitu Pulau Pahawang, Teluk Kilauan, Taman Nasional Way Kambas, Taman Nasional Bukit Barisan Selatan, dan Gunung Krakatau. Jumlah kunjungan wisatawannya, baik domestik maupun asing sudah mencapai 7,5 juta di tahun 2016. Angka tersebut naik 2 juta dari yang sebelumnya di tahun 2015 sebanyak 5,5 juta wisatawan. (Traveling.bisnis.com, 2017)

Ibu kota Provinsi Lampung adalah kota Bandar Lampung. Berbeda dengan beberapa Kabupaten di Provinsi Lampung yang memiliki banyak potensi wisata alam, Bandar Lampung sebagai pusat kota tidak banyak memiliki potensi wisata alam. Namun, kota Bandar Lampung masih memiliki peluang untuk mengembangkan wisata kulinernya. Sebagaimana yang disampaikan Dinas Pariwisata kota Bandar Lampung bahwa dalam rangka mendongkrak angka kunjungan wisatawan, maka akan dimaksimalkan potensi wisata kota Bandar Lampung dengan fokus kepada promosi wisata kuliner dan budaya (Lampungpro.com, 2017).

Saat ini, wisata kuliner sudah menjadi gaya hidup masyarakat perkotaan (Pandean \& Hansun, 2018). Orang senang untuk makan di luar rumah sambil menikmati suasana yang berbeda. Wisata kuliner juga menjadi hiburan tersendiri bagi para wisatawan. Ditambah lagi, banyak tayangan di televisi yang membahas tentang kuliner dari berbagai daerah di Indonesia, baik itu terkait rasa, tempat, suasana hingga harga. Hal tersebut membuat wisata kuliner semakin populer dan mendorong masyarakat untuk lebih mengenal masakan khas daerah di Indonesia.

Untuk menangkap peluang ekonomi dari wisata kuliner, salah satu caranya adalah membuat pemetaan lokasi-lokasi wisata kuliner strategis yang telah dan berpotensi untuk berkembang, serta membuat perencanaan dan program pengembangan wisata kuliner beserta dengan promosinya yang efektif dan optimal. Sebelum hal tersebut dilakukan, tentunya dibutuhkan informasi terkait kondisi wisata kuliner yang ada saat ini, seperti berapa jumlah wisata kuliner dan letak persebaran lokasinya. Sayangnya, informasi tersebut belum diakomodasi oleh pemerintah kota Bandar Lampung. Oleh karena itu, penelitian ini bertujuan untuk mengumpulkan informasi kuliner di Bandar Lampung dengan menggunakan web sebagai sumber data.

Saat ini, World Wide Web (WWW) atau yang biasa disebut dengan web, telah menjadi sumber informasi yang sangat besar dan sangat dikenal orang. Ketika seseorang ingin mencari suatu informasi, yang pertama kali diakses adalah web. Web terdiri dari miliaran dokumen yang saling berhubungan dan dikelola oleh jutaan orang. Web mudah untuk diakses, sehingga pencarian informasi melalui web dapat dilakukan dimana saja dan kapan saja. (Liu, 2011)

Penggalian informasi dari web atau web mining bisa menjadi salah satu solusi untuk mengumpulkan informasi wisata kuliner yang memanfaatkan web sebagai sumber data. Penggunaan cara tradisional, seperti survei, wawancara ataupun kuisioner, seringkali terkendala masalah dana dan geografis (Peng, Li, Wang, \& Chen, 2018). Di era digital saat ini, dimana banyak informasi yang dibagikan orang melalui internet, web mining diharapkan dapat menjadi solusi yang efektif untuk mencari informasi ataupun mengumpulkan informasi.

Istilah web mining pertama kali digunakan oleh Oren Etzioni. Web mining didefisinikan oleh Oren Etzioni sebagai penerapan teknik data mining ke data web untuk mengekstraksi informasi yang relevan dari sumber daya yang tersedia di web, sumber daya dapat berupa dokumen atau web service. (Sellamy, Fakhri, Boulaknadel, Moumen, \& Hafed, 2018). Proses web mining mirip dengan proses data mining, yang membedakan biasanya dalam proses pengumpulan datanya. Dalam proses data mining, data sudah dikumpulkan dalam database atau data warehouse. Sedangkan dalam web mining, pengumpulan data dari web menjadi tugas penting. Untuk mengunduh sejumlah halaman web secara otomatis, maka perlu dilakukan crawling. Crawling adalah proses menjelajahi web dan mengunduh halaman web secara otomatis untuk mengumpulkan informasi. Program yang khusus bertugas melakukan crawling disebut Crawler. (Liu, 2011)

Penelitian ini akan mengimplementasikan metode web crawling untuk mengumpulkan informasi wisata kuliner di Bandar Lampung. Sumber data yang digunakan adalah website TripAdvisor. TripAdvisor dipilih karena website tersebut merupakan situs wisata terbesar di dunia (Comscore.com, 2018). TripAdvisor memiliki lebih dari 661 juta ulasan dan opini tentang 7,7 juta akomodasi, maskapai penerbangan, objek wisata, dan restoaran. Situs TripAdvisor tersedia untuk 49 negara, dan menaungi komunitas wisata terbesar di dunia, dengan rata-rata 456 juta pengunjung setiap bulannya (Tripadvisor.com, 2017).

\section{METODE PENELITIAN}

Di era big data saat ini, jumlah data dan jenis informasi yang ada di web semakin meningkat. Dimana web telah menjadi sumber data, orang membutuhkan suatu cara untuk membantu mengumpulkan data dari web. Web crawling akan mencari halaman web melalui URL (Uniform Resource Locator), dan mengembalikan data yang bersangkutan ke pengguna secara langsung. Pengguna tidak perlu mengakses informasi dengan menelusuri halaman web satu per satu sehingga menghemat waktu dan tenaga serta meningkatkan 
akurasi pengumpulan data (Peng et al., 2018). Data yang sudah dikumpul kemudian dapat diolah dan dianalis lebih lanjut sesuai dengan kebutuhan pengguna.

Banyak penelitian terkait web mining yang melakukan web crawling untuk mengumpulkan data. Data yang di-crawling pun beragam, mulai dari film (Liu, Li, \& Wu, 2018), artikel berita (Hu, Wang, Wu, \& Acquisition, 2018), tweet (Kim \& Ha, 2016), lowongan pekerjaan (Peng et al., 2018), hingga informasi terkait minyak (Ren, 2018). Sumber objek yang dijadikan sumber informasi dapat terdiri dari beberapa website (Hu et al., 2018; Ren, 2018), ataupun fokus pada satu website seperti mencari informasi terkait film dari douban.com (Liu et al., 2018), serta dapat juga berasal dari media sosial seperti Twitter (Kim \& Ha, 2016) dan Weibo (Xia et al., 2015).

Penelitian ini akan melakukan web crawling untuk mengumpulkan informasi terkait lokasi atau alamat wisata kuliner di Bandar Lampung dari website TripAdvisor. Tidak banyak website yang khusus berisi informasi wisata kuliner di Bandar Lampung, namun ada beberapa yang berhasil ditemukan yaitu tripadvisor.com, jelajahlampung.com, dan jajanlampung.com. Akan tetapi, pada penelitian ini, TripAdvisor dipilih karena informasi yang ada didalamnya sudah dalam bentuk semistruktur sehingga lebih mudah untuk dilakukan proses ekstraksi informasi. Kebanyakan penelitian melakukan web crawling menggunakan Scrapy dari Phyton (Hu et al., 2018; Liu et al., 2018; Peng et al., 2018; Ren, 2018), pada penelitian ini web crawling dilakukan dengan menggunakan bahasa R.

Langkah-langkah yang dilakukan dalam melakukan web crawling dapat dilihat pada Gambar 1 .

\section{Initialize Seed URL and Fetch The Page}

Langkah pertama yaitu menginisialisasi Seed URL. Seed URL adalah URL awal yang sudah ditentukan oleh pengguna untuk melakukan crawling. Seed URL dalam penelitian ini adalah webpage utama TripAdvisor yang berisi daftar nama restoran yang ada di Bandar Lampung. Seed URL tersebut diakses halaman webnya.

\section{Link Extraction}

Selanjutnya, proses ekstraksi URL yang ada di halaman tersebut sebelumnya. URL yang belum dikunjungi disebut sebagai Frontier. Ektraksi dilakukan dengan menggunakan Regular Expression. Regular Expression akan mengidentifikasi pola URL dalam data teks. Selain URL, para tahapan ini diekstraksi juga nama restoran, yang dilakukan dengan cara mem-parsing berdasarkan tag HTML "title".

\section{URL Conversion}

URL hasil ekstraksi bentuknya masih belum baku (relative URL), sehingga tidak bisa langsung disimpan sebagai Frontier. Relative URL tersebut harus diubah terlebih dahulu menjadi bentuk yang baku (absolute URL). Konversi dilakukan dengan cara menambahkan URL utama dari website TripAdvisor ke depan relative URL.

Contoh relative URL ;

Restaurant_Review-g297722-d7309448-

Reviews-El_s_Coffee_House-

Bandar_Lampung_Lampung_Sumatra.html

Setelah Dikonversi menjadi absolute URL : https://www.tripadvisor.co.id/ Restaurant_Review-g297722-d7309448Reviews-El_s_Coffee_House-

Bandar_Lampung_Lampung_Sumatra.html



4. Save The Frontier

Absolute URL kemudian disimpan ke dalam repository untuk digunakan pada tahap selanjutnya.

5. Initialize Frontier and Fetch The page URL dari Frontier kemudian diambil kembali dari repository untuk diakses halaman webnya. Frontier pada penelitian ini berisi detail informasi terkait sebuah restoran.

\section{Information Extraction}


Langkah selanjutnya adalah mengekstraksi informasi dengan cara mem-parsing berdasarkan struktur halaman HTML, yang dilihat dari tag HTML. Pada penelitian ini beberapa informasi yang diekstraksi yaitu alamat, kota, kode pos, website, nomor telepon, rating, dan jumlah reviewer. Tabel 1 menunjukkan jenis informasi yang diekstraksi beserta tag-nya di dalam HTML.

\begin{tabular}{|c|c|c|}
\hline No & Informasi & Tag HTML \\
\hline 1 & Alamat & street-address \\
\hline 2 & Kota & locality \\
\hline 3 & Kode Pos & locality \\
\hline 4 & Website & website \\
\hline 5 & No. Telepon & phone \\
\hline 6 & Rating & rating \\
\hline 7 & $\begin{array}{c}\text { Jumlah } \\
\text { Reviewer }\end{array}$ & rating \\
\hline
\end{tabular}

Beberapa informasi ada yang tersimpan dalam HTML yang sama, seperti informasi kota dan kode pos yang tersimpan dalam tag "locality", serta rating dan jumlah reviewer yang tersimpan dalam tag "rating". Oleh karena itu, perlu dilakukan proses ektraksi selanjutnya. Ektraksi dilakukan dengan menggunakan Regular Expression.

7. Save The Information

Hasil informasi yang sudah didapatkan kemudian disimpan di dalam repository.

\section{HASIL DAN PEMBAHASAN}

Hasil web crawling dari website TripAdvisor berhasil mendapatkan 129 informasi terkait restoran atau wisata kuliner yang ada di Bandar Lampung. Namun, ada beberapa rincian informasi yang tidak lengkap, seperti tidak adanya informasi nomor telepon ataupun nama website. Tabel 2 menunjukkan persentase kelengkapan jumlah informasi yang didapatkan. Dapat dilihat juga bahwa ada informasi yang tidak ada sama sekali yaitu nama website. Hal tersebut disebabkan karena informasi tidak tersedia pada halaman website TripAdvisor.

Rata-rata informasi yang lengkap dan berhasil didapatkan adalah sebesar 71.1\%. Beberapa hasil informasi yang diperoleh dari website TripAdvisor dapat dilihat pada Tabel 3. Hasil informasi yang telah dikumpulkan tersebut dapat dianalisis lebih lanjut untuk berbagai kebutuhan seperti analisis spasial persebaran objek wisata kuliner, analisis rasio perkembangan jumlah wisata kuliner terhadap jumlah wisatawan yang datang, perencanaan pengembangan wisata kuliner di suatu wilayah secara spesifik maupun komprehensif, serta lokasi dan jenis kuliner yang paling diminati. Analisis-analisis tersebut dapat menjadi acuan untuk menentukan kebijakan pengembangan kota yang tepat, dalam rangka meningkatkan ekonomi daerah.

\begin{tabular}{|c|c|c|c|c|}
\hline No & $\begin{array}{c}\text { Jenis } \\
\text { Informasi }\end{array}$ & $\begin{array}{c}\text { Jumlah } \\
\text { Informasi } \\
\text { yang } \\
\text { Tersedia }\end{array}$ & $\begin{array}{c}\text { Jumlah } \\
\text { Informasi } \\
\text { yang Tidak } \\
\text { Tersedia }\end{array}$ & $\begin{array}{c}\text { Persentase } \\
\text { Kelengkapan } \\
\text { Informasi }\end{array}$ \\
\hline 1 & Alamat & 126 & 3 & $97,67 \%$ \\
\hline 2 & Kota & 126 & 3 & $97,67 \%$ \\
\hline 3 & Kode Pos & 74 & 52 & $57,36 \%$ \\
\hline 4 & Website & 96 & 30 & $74,42 \%$ \\
\hline 5 & $\begin{array}{l}\text { No. } \\
\text { Telepon }\end{array}$ & 0 & 129 & $0 \%$ \\
\hline 6 & Rating & 110 & 19 & $85,27 \%$ \\
\hline 7 & $\begin{array}{l}\text { Jumlah } \\
\text { Reviewer }\end{array}$ & 110 & 19 & $85,27 \%$ \\
\hline \multicolumn{4}{|c|}{$\begin{array}{r}\text { Rata-rata informasi yang tersedia dan } \\
\text { berhasil didapatkan }\end{array}$} & $71,1 \%$ \\
\hline
\end{tabular}

\section{KESIMPULAN}

Berdasarkan hasil penelitian yang telah dilakukan, dapat diambil kesimpulan bahwa web crawling dapat digunakan sebagai metode untuk mengumpulkan informasi dari web. Sumber yang dijadikan obyek web crawling dapat berasal dari website yang berkaitan dengan bidang tertentu seperti pariwisata, contohnya yaitu website TripAdvisor. Hasil dari web crawling dari website TripAdvisor menunjukkan bahwa ada beberapa rincian informasi yang tidak lengkap, dimana rata-rata informasi yang lengkap dan berhasil didapatkan adalah sebesar $71.1 \%$. Oleh karena itu, untuk pengembangan penelitian selanjutnya, dapat dipertimbangkan untuk menambah sumber website yang dijadikan obyek penelitian serta pemanfaatan media sosial seperti Twitter atau Instagram sebagai sumber informasi. Banyaknya obyek yang dijadikan sumber informasi tentunya akan semakin memperkaya informasi terkait wisata kuliner yang diperoleh.

Tabel 3. Contoh Informasi Hasil Web Crawling dari Website TripAdvisor

\begin{tabular}{|c|c|c|c|c|c|c|c|}
\hline No & Nama Kuliner & Alamat & Kode Pos & No Telepon & Website & Rating & $\begin{array}{c}\text { Jumlah } \\
\text { Reviewer }\end{array}$ \\
\hline 1 & Bakso Sonhaji Sony & $\begin{array}{l}\text { Jln. Wolter Monginsidi no. } \\
42 \mathrm{~A}\end{array}$ & 35119 & 085764139899 & $\begin{array}{l}\text { + Tambah } \\
\text { situs web }\end{array}$ & 4,0 & 187 \\
\hline 2 & Pempek 123 & Jl. Jend. Sudirman No. 15 & NA & 0721255791 & $\begin{array}{l}\text { + Tambah } \\
\text { situs web }\end{array}$ & 4,0 & 173 \\
\hline 3 & Jumbo Kakap & Jln. Ikan Kakap No. 45 & 35223 & 0721476159 & $\begin{array}{l}\text { + Tambah } \\
\text { situs web }\end{array}$ & 4,0 & 102 \\
\hline
\end{tabular}




\begin{tabular}{|c|c|c|c|c|c|c|c|}
\hline No & Nama Kuliner & Alamat & Kode Pos & No Telepon & Website & Rating & $\begin{array}{c}\text { Jumlah } \\
\text { Reviewer }\end{array}$ \\
\hline 4 & $\begin{array}{c}\text { Taman Santap Rumah } \\
\text { Kayu }\end{array}$ & $\begin{array}{l}\text { Jl. Arief Rahman Hakim No. } \\
\text { 45, Way Halim }\end{array}$ & 35141 & 21700666 & Situs Web & 4,0 & 95 \\
\hline 5 & $\begin{array}{l}\text { Begadang Resto } \\
\text { Convention Hall }\end{array}$ & Jl. Diponegoro no. 1 & NA & 0721474059 & Situs Web & 4,0 & 116 \\
\hline
\end{tabular}

\section{DAFTAR PUSTAKA}

COMSCORE.COM., 2018. Top 50 Multi-Platform Properties (Desktop and Mobile). [online] Tersedia di: $<$ https://www.comscore.com/Insights/Rankin gs> [Diakses 15 April 2018]

HU, C., WANG, Y., WU, L., \& ACQUISITION, A. D., 2018. Analysis of Hot News Based on Big Data, 17th International Conference on Computer and Information Science (ICIS), pp. 678-681.

KIM, S., \& HA, Y., 2016. Automated Discovery of Small Business Domain Knowledge Using Web Crawling and Data Mining, Big Data and Smart Computing (BigComp), pp. 481-484.

LAMPUNGPRO.COM., 2017. Promosi Wisata Bandar Lampung Fokus pada Kuliner dan Budaya. [online] Tersedia di $<$ https://lampungpro.com/post/2833/promosiwisata-bandar-lampung-fokus-pada-kulinerdan-budaya> [Diakses 27 Agustus 2018]

LIU, B., 2011. Web Data Mining : Exploring Hyperlinks, Contents, and Usage Data. $2^{\text {nd }}$ ed. Chicago : Springer.

LIU, X., LI, C., \& WU, D., 2018. Film and TV Actors Recommendation Based on SALSA Algorithm. 17th International Conference on Computer and Information Science (ICIS), pp. 372-376.

PANDEAN, S. S., \& HANSUN, S., 2018. Aplikasi Web untuk Rekomendasi Restoran Menggunakan Weighted Product. Jurnal Teknologi Informasi dan Ilmu Komputer (JTIIK), pp. 87-95.

PENG, D., LI, T., WANG, Y., \& CHEN, C. L. P., 2018. Research on Information Collection Method of Shipping Job Hunting Based on Web Crawler. Eighth International Conference on Information Science and Technology (ICIST), pp. 57-62.

REN, Y., 2018. A Framework of Petroleum Information Retrieval System Based On Web Scraping With Python. 15th International Conference on Service Systems and Service Management (ICSSSM), pp. 1-6.

SELLAMY, K., FAKHRI,Y., BOULAKNADEL, S., MOUMEN, A., \& HAFED, K., 2018. Web Mining Techniques and Appliacations : Literature Review and a Proposal Approach to Improve Performance of Employment for
Young Graduate in Morocco. Intelligent System and Computer Vision (ISCV), pp. 1-5.

TRAVELLING.BISNIS.COM., 2017. Lampung Berbenah Siapkan Objek Wisata Unggulan. [online] Tersedia di <http://traveling.bisnis.com/read/20170319/2 24/638262/lampung-berbenah-siapkan-objekwisata-unggulan>

TRIPADVISOR.COM., 2017. Tentang TripAdvisior. [online] Tersedia di: <https://tripadvisor.mediaroom.com/id-aboutus> [Diakses 21 Agustus 2018]

XIA, J., WAN, W., LIU, R., CHEN, G., \& FENG, Q., 2015. Distributed Web Crawling: A Framework for Crawling of Micro-Blog Data. International Conference on Smart and Sustainable City and Big Data (ICSSC), pp. 62-68. 
Halaman ini sengaja dikosongkan 